Original Article

\title{
Effects of low light on the stability of the head and pelvis of the healthy elderly
}

\author{
Jin-Seung Chol, $\mathrm{PhD}^{1,2)}$, Dong-Won Kang, MS ${ }^{1)}$, Jeong-Woo Seo, MS ${ }^{1)}$, \\ Dae-Hyeor Kim, BS ${ }^{1)}$, Seung-Tae Yang, BS ${ }^{1)}$, Gye-Rae Tack, PhD $\left.{ }^{1,2}\right)^{*}$ \\ 1) School of Biomedical Engineering, Konkuk University: 268 Chungwon-daero, Chungju, Chungbuk \\ 380-701, Republic of Korea \\ 2) BK21 Plus Research Institute of Biomedical Engineering, Konkuk University, Republic of Korea
}

\begin{abstract}
Purpose] The purpose of this study was to evaluate the changes in body stability of the elderly while walking on even surface ground under low light. [Subjects] Ten young males and ten elderly males participated in this experiment. [Methods] Each subject walked along a $7 \mathrm{~m}$ walkway five times at their preferred walking speed under normal ( $>300$ lux, NORM) and low light conditions ( $<5$ lux, LOW). To compare the changes in body stability, the root mean square of acceleration (RMSacc) at the head and pelvis was used. [Results] The results show that the body stability of young adults showed a similar RMSacc in all directions at the head and pelvis between the normal and low light walking conditions. In contrast, the RMSacc in all directions at the head and pelvis during low light walking by elderly adults was significantly greater than that of normal light walking. [Conclusion] It was confirmed that, despite walking on even ground, low light condition affects the body stability of the elderly. To clearly evaluate the effect of low light with aging on gait pattern, further study will be necessary to perform additional experiments under various environmental conditions to investigate walking speed, multi-tasking, stairs, and uneven walkway performance.
\end{abstract}

Key words: Low light, Even-ground walking, Body stability

(This article was submitted Jul. 1, 2015, and was accepted Jul. 31, 2015)

\section{INTRODUCTION}

In general, the physical ability of the elderly is lower than that of the young. The differences could be caused by compensation strategies crucial for gait ability, such as slow walking speed, or reduced range of motion of the joints for improving body stability during walking ${ }^{1,2)}$. Falls by the elderly can cause many problems for their physical health. Falls primarily occur due to both a decline in physical ability due to aging and environmental causes. The environmental causes can be reduced by finding risk factors and deteriorations in physical and sensory functions ${ }^{3)}$. Visual information about the environment can be used to maintain body balance ${ }^{4}$. However, low lighting, one of the causes of falls by the elderly, is common in daily living. Insufficient visual information due to low lighting, can increase the risk of falling due to unseen obstacles or reduced body stability in daily living ${ }^{5)}$. In addition, visual information plays a crucial role in the ability to avoid obstacles as well as in the proactive control of dynamic stability and route planning during level walking ${ }^{6,7)}$. Nevertheless, most previous studies have

*Corresponding author. Gye-Rae Tack (E-mail: grtack@kku. ac.kr)

(C)2015 The Society of Physical Therapy Science. Published by IPEC Inc This is an open-access article distributed under the terms of the Creative Commons Attribution Non-Commercial No Derivatives (by-ncnd) License $<$ http://creativecommons.org/licenses/by-nc-nd/3.0/> . focused on recognizing and avoiding obstacles, and walking on an uneven surface or stairs ${ }^{8-10)}$. In other words, gait patterns during even-surface walking may change with lack of visual information, especially in the case of the elderly, who have a different balance strategy or method of maintaining body balance while walking than the young ${ }^{2}$. It is necessary to identify the effect of insufficient visual information on walking patterns by examining even-surface walking under low lighting.

A recent study confirmed that there were significant differences in walking speed and lower limb kinematics (i.e., toe clearance) between the young and the elderly during level walking under low light. Nevertheless, the body stability of both groups was constantly maintained ${ }^{7}$. The authors of that considered that body stability was maintained by the elderly, because the subjects were walking on an even surface. However, in another study, which evaluated body stability, the medio-lateral range of motion at the center of mass was used to record the actual body stability. Therefore, as a supplementary work, the goal of this study was to evaluate the changes in body stability at the head and the pelvis of the elderly while walking on an even surface under low light.

\section{SUBJECTS AND METHODS}

Ten healthy young males $(21.6 \pm 1.7$ years, $173.4 \pm$ $3.9 \mathrm{~cm}, 67.8 \pm 12.7 \mathrm{~kg})$ and ten elderly adult males $(72.0 \pm$ 5.5 years, $161.5 \pm 5.5 \mathrm{~cm}, 64.2 \pm 5.9 \mathrm{~kg}$ ) without a medical 
Table 1. Walking speed and the stance ratio

\begin{tabular}{|c|c|c|c|c|}
\hline & & & Normal light & Low light \\
\hline \multirow{4}{*}{$\begin{array}{l}\text { Walking speed } \\
\left(\mathrm{m} / \mathrm{s}^{2}\right)\end{array}$} & \multirow{2}{*}{ Old } & mean & 0.85 & 0.86 \\
\hline & & (SD) & $(0.14)$ & $(0.15)$ \\
\hline & \multirow{2}{*}{ Young } & mean & $1.40^{*}, \dagger$ & $1.30^{*}, \dagger$ \\
\hline & & (SD) & $(0.15)$ & $(0.13)$ \\
\hline \multirow{4}{*}{$\begin{array}{l}\text { Stance ratio } \\
(\%)\end{array}$} & \multirow{2}{*}{ Old } & mean & 59.41 & 58.94 \\
\hline & & (SD) & $(1.65)$ & $(2.36)$ \\
\hline & \multirow{2}{*}{ Young } & mean & 54.72 & 54.53 \\
\hline & & (SD) & (6.33) & $(5.55)$ \\
\hline \multirow{4}{*}{$\begin{array}{l}\text { Toe clearance } \\
(\mathrm{cm})\end{array}$} & \multirow{2}{*}{ Old } & mean & 2.2 & 2.1 \\
\hline & & (SD) & (0.4) & $(0.3)$ \\
\hline & \multirow{2}{*}{ Young } & mean & $2.5^{*}$ & $3.1^{*}$ \\
\hline & & (SD) & (1.0) & $(0.3)$ \\
\hline
\end{tabular}

*: significant difference between lighting conditions in each group, $\mathrm{p}<0.05$; $\uparrow$ : significant difference between the elderly and young under each lighting condition, $p<0.05$

history of a problem in the lower extremities for the past 1 year and no problems with vision participated in this experiment. All the elderly participants could walk more than 10 meters without the help of others, and their motor function was in the normal range at level five of the functional ambulation category (FAC). The protocol of this study was approved by the Ethics Committee of Konkuk University. Experimental procedures were explained to the subjects, and their written consent was obtained.

All subjects walked five times on a $7 \mathrm{~m}$ even-surface walkway at their preferred walking speed under normal light (>300 lux, NORM) and under low light ( $<5$ lux, LOW) conditions. A three-dimensional motion-capture system (Motion analysis Corps., USA) with six infrared cameras was used for data acquisition at a sampling frequency of $120 \mathrm{~Hz}$. Six reflective markers with a diameter of $8 \mathrm{~mm}$ were attached to the head, lumbar spine (between L4 and L5) of the body, and both heels and toes. The experimental lighting condition (Illumination) was measured at the middle of the walkway using a digital illuminometer (LX801, NICETY, China) with 1 lux resolution and a $0-50000$ lux measuring range. For the low light condition, the intensity of illumination was reduced when the subject started walking. For noise reduction of the position (3D motion) data provided by each mark, the data were filtered using a 2nd order zero-lag low-pass Butterworth filter with a $7 \mathrm{~Hz}$ cut-off frequency. Using the finite difference equation, the acceleration data were calculated from the position data.

For the comparison of gait and body stability, measurements were recorded of various parameters including walking speed, the stance ratio, and root mean square acceleration (RMSacc) at the head and pelvis. RMSacc is used to provide an indication of the average magnitude of acceleration in each direction during a complete walking trial, and in this study it represents the stability at the head and pelvis ${ }^{11)}$. All calculations of these parameters were conducted using MATLAB v7.0 (Mathworks Inc., USA). SPSS v17.0k (PASW, SPSS Inc., USA) was used for statistical analysis. The paired t-test and independent t-test were performed for comparison of the lighting conditions within each group and between groups, respectively. The significance level was chosen as $\alpha=0.05$.

\section{RESULTS}

The walking speed and stance phase of both groups are presented in Table 1. The walking speed under both lighting conditions in the young group was faster than in the elderly group (normal light $\mathrm{p}=0.000$; low light $\mathrm{p}=0.000$ ). A significant difference was observed in the walking speed of the young group between the lighting conditions $(\mathrm{p}=0.000)$, but no significant difference was observed in the walking speed of the elderly group between the lighting conditions $(p=0.859)$. Because of the lower walking speed of the elderly group, the stance ratio of the elderly group was higher than that of the young group, but the difference was not significant. Toe clearance (TC) showed a significant difference between the groups under all lighting conditions (normal light: $p=0.036$, low light: $p=0.000$ ). Under both lighting conditions, the average toe clearances of the elderly group did not change much and the difference was not significant (normal light $=2.2 \mathrm{~cm}$, low light $=2.1 \mathrm{~cm}, \mathrm{p}=0.183$ ). For the young group, a large difference was observed in average toe clearances between the lighting conditions (normal light $=2.5 \mathrm{~cm}$, low light $=3.1 \mathrm{~cm}$ ), but it was not statistically significant $(\mathrm{p}=0.149)$.

The results of head and pelvis stability of both groups due to lighting conditions are presented in Table 2 . In the results of the elderly group, significant differences were found in all directions at the head and pelvis between the normal and low light conditions (head: anterio-posterior (AP) $p=0.003$; mediolateral (ML) $\mathrm{p}=0.001$, vertical (VER) $\mathrm{p}=0.002$; body: AP $p=0.004$; ML $p=0.000$, VER $p=0.000$ ). In the young group, no significant difference was found between the lighting conditions in head or pelvis stability. Under the normal lighting condition, a significant difference was found in the AP direction of pelvis stability between the two groups. Under the low lighting condition, significant differences were found in all directions of head and pelvis stability between the two groups (head: AP $p=0.029$; ML $p=0.004$, VER 
Table 2. Head and body stability

\begin{tabular}{|c|c|c|c|c|c|c|c|}
\hline \multirow{2}{*}{\multicolumn{2}{|c|}{$\begin{array}{l}\text { Head stability } \\
\text { (RMSacc) }\end{array}$}} & \multicolumn{3}{|c|}{ Normal light } & \multicolumn{3}{|c|}{ Low light } \\
\hline & & AP & ML & VER & $\mathrm{AP}$ & ML & VER \\
\hline \multirow{2}{*}{ Old } & mean & 0.02 & 0.14 & 0.24 & $0.07^{*}, \dagger$ & $0.48^{*}, \dagger$ & $0.88^{*}, \dagger$ \\
\hline & (SD) & $(0.01)$ & $(0.08)$ & $(0.13)$ & $(0.05)$ & $(0.33)$ & $(0.62)$ \\
\hline \multirow{2}{*}{ Young } & mean & 0.03 & 0.14 & 0.27 & 0.03 & 0.19 & 0.37 \\
\hline & (SD) & $(0.01)$ & $(0.09)$ & $(0.17)$ & $(0.03)$ & $(0.11)$ & $(0.22)$ \\
\hline \multirow{2}{*}{\multicolumn{2}{|c|}{$\begin{array}{l}\text { Pelvic stability } \\
\text { (RMSacc) }\end{array}$}} & \multicolumn{3}{|c|}{ Normal light } & \multicolumn{3}{|c|}{ Low light } \\
\hline & & AP & ML & VER & AP & ML & VER \\
\hline \multirow{2}{*}{ Old } & mean & $0.04^{\dagger}$ & 0.43 & 0.84 & $0.11^{*}$ & $1.09^{*, \dagger}$ & $2.14^{*}, \dagger$ \\
\hline & (SD) & $(0.03)$ & $(0.30)$ & $(0.57)$ & $(0.07)$ & $(0.46)$ & $(0.87)$ \\
\hline \multirow{2}{*}{ Young } & mean & 0.08 & 0.52 & 0.94 & 0.09 & 0.50 & 0.87 \\
\hline & (SD) & $(0.03)$ & $(0.23)$ & $(0.43)$ & $(0.06)$ & $(0.29)$ & $(0.51)$ \\
\hline
\end{tabular}

AP: anterior-posterior direction, ML: medio-lateral direction, VER: vertical direction; RMSacc: root mean square of acceleration; *: significant difference between light conditions in each group, $\mathrm{p}<0.05 ; \uparrow$ : significant difference between the elderly and young under each lighting condition, $\mathrm{p}<0.05$

$\mathrm{p}=0.008$; pelvis: $\mathrm{ML} \mathrm{p}=0.001$, VER $\mathrm{p}=0.000)$, except the AP direction of pelvic stability $(\mathrm{p}=0.548)$.

\section{DISCUSSION}

A previous study reported that the young showed decreased walking speed and increased toe clearance while walking under low light, while the elderly did not show any changes in these variables. However, although there was a significant difference in gait adaptation between the elderly and young groups due to low light, no change was observed in the medio-lateral range of motion (ROM) at the center of mass (COM), which represents body stability, between the two groups ${ }^{7)}$. In other words, no significant difference was shown in the body stability of the two groups due to low light. These results confirmed that even though there was a difference in gait pattern (walking speed, stance phase ratio, and TC) between the two groups while walking under low light, the body stability of both groups was maintained in level walking without disturbance. The results of the present study complement the research of the previous study, in which the medio-lateral range of motion of the COM was used to represent stability. In this present study, RMSacc, which is commonly used to evaluate physical stability, was used to investigate head and pelvic stability ${ }^{11)}$.

The results of the elderly group in the present study show that RMSacc at the head as well as at the pelvis increased significantly, while no difference was observed in the RMSaccs of the young group due to low light condition (Table 2). In other words, despite level walking, the body stability under low light of the elderly was reduced, and that of the young was maintained. To summarize the current and previous studies, young adults showed changes in gait pattern (such as decreased walking speed and increased toe clearance $)^{7)}$, but their head and pelvic stabilities were maintained, whereas the elderly did not show changes in gait pattern, but their head and pelvic stabilities were reduced.

According to a previous study which investigated agerelated differences in stability between level- and irregularsurface walking under normal light, RMSaccs of the elderly were smaller or similar to those of the young. The authors concluded that this was because the elderly adopt a more conservative gait pattern than the young to compensate for their lower physical abilities by reducing walking speed and step length ${ }^{11)}$. Average RMSaccs in the present study were similar to the results of a previous study, except during low light walking by the elderly. This demonstrates that the effect of low light on the elderly is greater than on young adults. From the point of view that the effects of light according to age may differ, this agrees with the result of Hallemans et al. ${ }^{12,13)}$, who showed there were significant differences in step times and kinematics parameters between adults and children caused by vision deprivation.

On the other hand, according to the results of Thies et al., an irregular surface has a greater effect on the gait variability of elderly adults than on that of young adults, while low light only slightly affected gait variability ${ }^{12)}$. Although it has been reported that step length is related to body stability'), the research of Thies et al. is limited as it only investigated step width and step time variability ${ }^{14}$.

In other previous studies, various studies of the walking environment (such as stair descent ${ }^{6}$ ), uneven surface ${ }^{12)}$, and obstacle $^{10)}$ ) were performed. Most results show differences in gait parameters or stability between young and elderly groups. The level of difficulty of these walking conditions was thus greater than those of walking on level ground. According to previous studies using stair descent ${ }^{6)}$ and obstacles ${ }^{10)}$, toe clearance increases in the young in response to low light, whereas the elderly reduce or maintain the same toe clearance ${ }^{6,10)}$. The authors of those reports claimed that these differences are one of the factors that increase the fall risk of the elderly. Thus, the results of this study agree with the results of previous studies, showing that walking on level ground under low light has an effect on body stability.

These results can be used for the determination of the age-related effects of various walking conditions under low light, such as walking tests using various levels of difficulty, and age-related differences in gait adaptation. In a future study, to clarify the effect of low light, it will be necessary to perform additional experiments using various walking envi- 
ronments (i.e., uneven surface and obstacles) and a variety of subjects with a range of health conditions and ages.

\section{ACKNOWLEDGEMENT}

This work was supported by Konkuk University.

\section{REFERENCES}

1) Menz HB, Lord SR, Fitzpatrick RC: A structural equation model relating impaired sensorimotor function, fear of falling and gait patterns in older people. Gait Posture, 2007, 25: 243-249. [Medline] [CrossRef]

2) Moe-Nilssen R, Helbostad JL, Akra T, et al.: Modulation of gait during visual adaptation to dark. J Mot Behav, 2006, 38: 118-125. [Medline] [CrossRef]

3) Sturnieks DL, St George R, Lord SR: Balance disorders in the elderly Neurophysiol Clin, 2008, 38: 467-478. [Medline] [CrossRef]

4) Patla AE: Understanding the roles of vision in the control of human locomotion. Gait Posture, 1997, 5: 54-69. [CrossRef]

5) Brooke-Wavell K, Perrett LK, Howarth PA, et al.: Influence of the visua environment on the postural stability in healthy older women. Gerontology, 2002, 48: 293-297. [Medline] [CrossRef]
6) Hamel KA, Okita N, Higginson JS, et al.: Foot clearance during stair descent: effects of age and illumination. Gait Posture, 2005, 21: 135-140. [Medline] [CrossRef]

7) Choi JS, Kang DW, Shin YH, et al.: Differences in gait pattern between the elderly and the young during level walking under low illumination. Acta Bioeng Biomech, 2014, 16: 3-9. [Medline]

8) Ostrosky KM, VanSwearingen JM, Burdett RG, et al.: A comparison of gait characteristics in young and old subjects. Phys Ther, 1994, 74: 637644, discussion 644-646. [Medline]

9) Paroczai R, Bejek Z, Illyes A, et al.: Gait parameters of healthy, elderly people. Facta Universitatis. Ser Phys Educ Sport, 2006, 4: 49-58.

10) Cho SY, Ryu YU, Je HD, et al.: Effects of illumination on toe clearance and gait parameters of elderlyer adults when stepping over an obstacle: a pilot study. J Phys Ther Sci, 2013, 25: 229-232. [CrossRef]

11) Menz HB, Lord SR, Fitzpatrick RC: Age-related differences in walking stability. Age Ageing, 2003, 32: 137-142. [Medline] [CrossRef]

12) Hallemans A, Beccu S, Van Loock K, et al.: Visual deprivation leads to gait adaptations that are age- and context-specific: I. Step-time parameters. Gait Posture, 2009, 30: 55-59. [Medline] [CrossRef]

13) Hallemans A, Beccu S, Van Loock K, et al.: Visual deprivation leads to gait adaptations that are age- and context-specific: II. Kinematic parameters. Gait Posture, 2009, 30: 307-311. [Medline] [CrossRef]

14) Thies SB, Richardson JK, Ashton-Miller JA: Effects of surface irregularity and lighting on step variability during gait: a study in healthy young and older women. Gait Posture, 2005, 22: 26-31. [Medline] [CrossRef] 